\title{
Pre-release access to official statistics: The deep difference between granting privileged pre-release access to the government and to the media
}

\author{
Giorgio Alleva ${ }^{\mathrm{a}, *}$ and Marina Gandolfo ${ }^{\mathrm{b}}$ \\ ${ }^{a}$ University Sapienza of Rome (Former President of Istat), Rome, Italy \\ ${ }^{\mathrm{b}}$ Istat, Rome, Italy
}

\section{Executive summary}

It is not enough to declare and show data quality and sound methodologies to build and maintain trust among users and citizens. The National Statistical Offices (NSOs) are aware that trustworthiness is the real treasure to defend and to increase, especially in this fake news and post-truth era. Reputation is developed step by step, but a simple mistake, an unfortunate event, can undermine it.

Equal access to official statistics by users is an important pillar for impartiality and independence, broadly recognized as best practice for adhering to the UN Fundamental Principles and the EU Code of Practice. In this paper, privileged pre-release access to outside user is considered. The difference between privileged access by the government and the media is discussed, providing an assessment of risk and negative impact according to the characteristics, motivations and contexts in which they occur.

The thesis is that pre-release access reserved for the government, independently of motivations and the time of anticipation in respect to the scheduled release, is always to be excluded. For a statistical agency pre-release to the government is not a case of agility or flexibility; it is not a case of tailored service, or a way to be more

${ }^{*}$ Corresponding author: Giorgio Alleva, University Sapienza of Rome (Former President of Istat) Rome, Italy. E-mail: giorgio.alleva @ uniroma1.it. relevant or timely. It is only a breach of the principle of impartiality; a form of privilege that damages the opposition counterparts, but also journalists and citizens.

The question becomes, how do we deal with the need to provide information to the government in advance of the release calendar in case of an urgent information need suddenly came out by users. A possible way to deal with this problem is to make available publicly the release of data with respect to the scheduled timing avoiding any breach of the principle of equal access, explaining the motivation to anticipate the release of data and the fact that only in an exceptional cases is information to be pre-released.

The case of pre-release to the media is different. NSOs cannot only make numbers every day, we must facilitate the comprehension of the data, we produce. Partnership with the scientific community and the media is strategic for the correct communication and interpretation of data. For sensitive and much expected data there could be a reinforcement of data security; a presentation to the media and disseminate press agencies a short time before the planned time to publish (30 minutes, currently), by the production and communication staff, in a specially designed press room to guarantee the embargo. Full transparency on participation should be designed.

In this paper, cases of appropriate pre-release access and secure "lock-up" facility experience are discussed. Recent experiences in this direction of the Italian National Statistical Institute (Istat) are presented. 


\section{Equal access to official statistics by users: $A$ recognized value for independence and impartiality of official statistics}

In this era of great uncertainty about the future, official statistics have to play an important role in developing and producing information for making decisions. Therefore, it is necessary to have qualified and independent National Statistical Offices (NSOs) and international organization dealing with statistical data.

We have soft laws and tools which clearly express the concept of equal access as a value for independence and impartiality. Equal access to official statistics by users is an important pillar for impartiality and independence, broadly recognized as best practice for adhering to the UN Fundamental Principles and the EU Code of Practice. The possibility of privileged pre-release access to outside user is also considered.

To explain the thesis of the paper, it is useful to refer to the current legal framework in which the NSOs move, highlighting the recent developments and the persistence of discretionary actions on the subject in question.

The UN Fundamental Principles include Equal Access to Statistical Releases, strictly together with Relevance and Impartiality (see Table 1).

Also, the European Statistics Code of Practice (ESCOP) in its last revision in $2017^{1}$ includes aspects related to the access to statistical releases and the accessibility on an equitably basis by all users. Bridges and links can be found in the Principle on Professional Independence (Principle 1) and in the Principle on Impartiality and Objectivity (Principle 6).

In the ESCOP, in Principle 1, the factors of independence are well considered from the perspective of the Institution (NSO and Eurostat) and the perspective of the Head of the NSO and Eurostat (and where appropriate the heads of the other statistical authorities).

Clear links to statistical release are included in Indicator 1.4; it states that the sole responsibility for deciding on statistical methods, standards and procedures, and on the content and timing of statistical releases are the responsibility of the heads of NSOs. Indicator 1.6 expects that statistical releases are clearly distinguished and issued separately from political statements and policy declaration.

\footnotetext{
${ }^{1}$ The European Statistics Code of Practice (ESCOP) established in 2005 had several revisions; the last revision takes into account recent development, innovation and modernization of European statistics. It was approved by the European Statistical System Committee in November 2017.
}

Specific aspects of a release calendar and pre-release are clearly mentioned within Principles 6 on Impartiality and Objectivity: Indicator 6.7 has been integrated taking into account experiences by some countries and situations in which a clear mechanism has to be reflected when pre-release access is in place. The possibility of privileged pre-release access to outside user is also considered.

In general, a clear sentence is present on the independence to decide on the time and content of statistical release; thus, it takes into account factors strictly related to the professional independence of the heads of NSOs and of the NSO itself. At the same time, it is remarked that there is a possibility that pre-release access could happen, but only with a well justified reason and it must be clearly publicized.

The revision made in 2017 with respect to the previous ESCOP on the issue of access to statistical release is summarized in Table 2.

\section{Pre-release access reserved for the government in order to be more relevant or agile in supporting decision making? Is it different for the media?}

For a long time, NSOs have been aware that it is not enough to declare and show data quality and sound methodologies to build and maintain trust among users and citizens. Even when NSOs are committed to invest a lot to be able to exploit new data sources and digital technologies, to build new integrated informative infrastructures redefining the entire cycle of the data production and dissemination, the real treasure of the NSOs are to defend and to increase trustworthiness, especially in this fake news and post-truth era.

The institutional environment, the professional independence and scientific competences, as well the strict compliance with the principles and the global standards to assure impartiality and objectivity of the official statistics, represent the crucial preconditions of trust in the statistical agencies and in the statistical information they produce. Reputation is developed step by step, but a simple mistake, an unfortunate event, can undermine all the effort done in building trust.

Pre-release access reserved for the government, independently of motivations and of the time, is always to be excluded. Transparency in reporting the circumstances of the breach, the impact and $c$ orrective actions to prevent re-occurrence are generally well developed by NSOs, but they are not sufficient to make people not 
Table 1

Pre-release in the UN Fundamental Principles

\begin{tabular}{|c|c|c|}
\hline $\begin{array}{l}\text { Relevance, impartiality and equal access } \\
\text { (Principle 1) }\end{array}$ & $\begin{array}{l}\text { Impartiality and equal access (part } \\
\text { of Principle 1) }\end{array}$ & Equal access to statistical releases \\
\hline $\begin{array}{l}\text { Official statistics provide an indispensable element } \\
\text { in the information system of a democratic society, } \\
\text { serving the Government, the economy and the public } \\
\text { with data about the economic, demographic, social } \\
\text { and environmental situation. } \\
\text { To this end, official statistics that meet the test of } \\
\text { practical utility are to be compiled and made } \\
\text { available on an impartial basis by official statistical } \\
\text { agencies to honour citizens' entitlement to public } \\
\text { information. }\end{array}$ & $\begin{array}{l}\text { The use and benefit of official statis- } \\
\text { tics is dependent on their credibility } \\
\text { and confidence towards users. } \\
\text { Professional independence of } \\
\text { statistical agencies, scientific } \\
\text { competence of their staff and } \\
\text { impartiality are the crucial } \\
\text { preconditions of trust in official } \\
\text { statistics. }\end{array}$ & $\begin{array}{l}\text { All users have equal access to statistical re- } \\
\text { leases at the same time. } \\
\text { There is no privileged access for governmen- } \\
\text { tal representatives. Any privileged pre-release } \\
\text { access to any outside user is limited, con- } \\
\text { trolled and publicised. } \\
\text { If leaks of statistical information occur, } \\
\text { pre-release arrangements are revised so as to } \\
\text { ensure impartiality. To that purpose specific } \\
\text { procedures are put in place and make } \\
\text { publicised. }\end{array}$ \\
\hline
\end{tabular}

Table 2

Pre-release in the European Statistics Code of Practice (ESCOP) - revisions 2011 and 2017

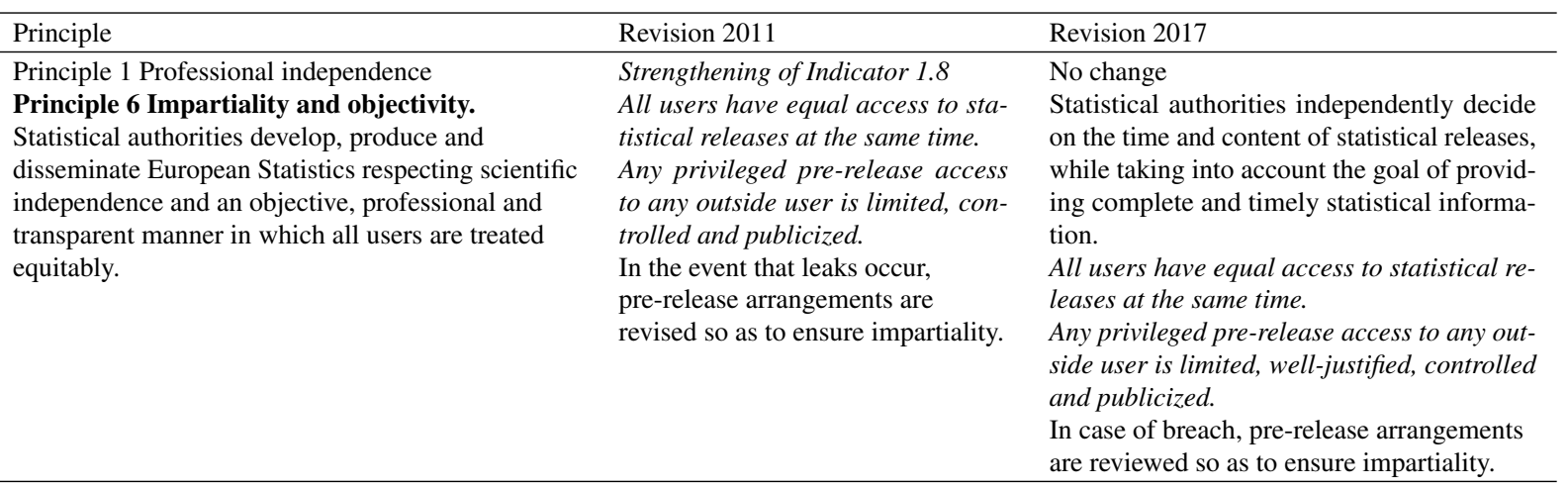

think of a special privilege, a lack of independence of the statistical agency from the political power.

For a statistical agency pre-release to the government is not a case of agility or flexibility, it is not a case of tailored service, or a way to be more relevant or timely. It is only a breach of the principle of impartiality, a form of privilege that damages the opposition counterparts, but also journalists and citizens and a limitation to equal access.

The issue is, how do we deal with the need to provide information to the government in advance of the release calendar in case of urgent information need suddenly came out by users?

A possible way to deal with this problem is to provide to all the release of data with respect to the scheduled timing avoiding any breach of the principle of equal access, and explaining the motivation for data pre-release. Only in exceptional cases is information pre-released.

The case of pre-release to the media is different. NSOs cannot only make numbers every day, NSOs must facilitate the comprehension of the data, we produce. The point is to disseminate not only measures but also the level of their confidence/variability, their hetero- geneity among different sub-populations, the connections with other variables, that can represent their determinants or impacts. Partnership with the scientific community and the media is strategic for the correct communication and interpretation of data. For sensitive and much expected data there could be a reinforcement of data security; a presentation to the press agencies a short time before the planned time to publish (30 minutes, currently), by the production and communication staff, in a specially designed press room to guarantee the embargo. Full transparency on participation should be designed.

\section{Pre-release to media: The embargo policy in the Istat experience}

In this Section, two embargo policies for privileged access to media of statistical products by Istat are presented. The first regards press releases and the second releases of complex products. Both are aimed at facilitating a better comprehension and communication by media, fully respecting the ESCOP principles. 
The first case concerns the embargo covering the issue of press releases with attendance at presentation briefing. With the lock-up system, Istat facilitates accredited news agencies in their work of mediation of statistical content, ensuring impartial, simultaneous, without privileged disclosure. The controlled access mode in lock-up mode includes:

- Taking place 30 minutes before the release of the press releases;

- Taking place in the Institute's Press Room behind closed doors, without the possibility of communicating with the outside;

- There is a data illustration briefing by Istat representatives.

During this period of time the representatives of the press agencies have the opportunity to prepare the texts of the press launches and ask for clarifications. Failure to comply with the lock-up system may lead to temporary - or complete, in the case of repeated infractions suspension of access to the press room.

The main phases of the new system are the following:

1. During the embargo, after the authentication with a pre-assigned individual user (at least for the "usual participants" at the briefing), the representatives of the press agencies are automatically connected to the Istat's protected internal network - wired for the agencies if they have fixed workstations, wi-fi for those without a workstation - from which Internet access is not possible.

2. Meanwhile, the press office staff will upload the press release and its attachments to the protected web area (available at http://agenzie.istat.it/comun icato) thus making them available for downloading to press agency representatives.

3. Fifteen seconds before the time set for the release, the staff of the press office enables the network from the portal http://agenzie.istat.it/sala-stampa. At this point, the agencies that use their own links are associated with their own network while those that have resorted to the Istat network have free access to the Internet. It is understood that the representatives of the press agencies will be able to send the text made only after having received the authorization (the so-called "Via") from a person in charge of the press office.

The representatives of the press agencies that intend to accredit themselves, delegated with formal communication by the editor in charge of the publication, are asked to fully accept the general conditions contained in this document, which are binding for participation.
A second case concerns the embargo for the release of complex products. It is meant to facilitate journalists' work during the release of particularly complex or datarich products.

In the case of a book publication, the volume is delivered to the newsrooms 24 hours prior to the publication date. Access credentials to preview online products are required. Also, journalists may be invited to attend an embargo press conference during which the editors of the volume will illustrate the most important aspects.

In all cases, press-office staff will monitor the media until the pre-established publication time, in order to ensure compliance with the embargo.

As evidence of full compliance with the ESCOP, it is important to note that: there is no choice by Istat of the media to which to grant or not to grant the privileged access. Any professionally accredited subject who requests it, can get the access granted; and the access is implemented only after an trial run shows that the technological infrastructure and the procedure that guarantees absolute confidentiality towards the world outside of the information during the time of the embargo, is working.

\section{Future challenges and developments}

The real challenge is to develop the access to statistical information providing equal access but taking into account also the user needs. A well-designed calendar of releases, not only based on NSOs internal elements but attentive to the needs and deadlines of the main users, and the flexibility to redefine it in advance, according to predefined rules, are important points to improve data quality.

Ideally, a new approach to respond to users' demand should start from the new data ecosystem and from an updating mechanism of data. In particular, developing a data production model based on the integration of different sources and designing a continuously updating approach is important. Full transparency on the updating mechanism will be crucial. This means developing the release calendar more oriented to statistical services (integrated analysis, in depth focus) and less on data production.

Is the media ready to take advantage of this new approach? NSOs could contribute by facilitating their capacity and enhancing their skills. However, this is not something the NSOs can do alone. We think that academia and international organization dealing with statistics and capacity development can also effectively add their contribution in partnership with NSOs and the national, European and global Statistical Systems. 


\section{References}

[1] Eurostat (2017). European Statistics Code of Practice for the National Statistical Authorities and Eurostat, Adopted by the EESC 16th November 2017 https://ec.europa.eu/eurostat/documents/ 4031688/8971242/KS-02-18-142-EN-N.pdf/e7f85f07-91db4312-8118-f729c75878c7.

[2] Eurostat (2011). European Statistics Code of practice for the National and Community Statistical Authorities. Catalogue no. KS-3211-955-EN-C. http://ec.europa.eu/eurostat/documents/ 3859498/5921861/KS-32-11-955-EN.pdf/5fa_1_ebc6-90bb43fa-888fdde03247_1_e15.
[3] Istat (2018). L'embargo: una politica per veicolare informazioni corrette https://www.istat.it/it/informazioni-e-servizi/per-i-gior nalisti/embargo.

[4] United Nations Statistics Division, UNSD (2014). Fundamental Principles of Official Statistics. Resolution A/68/L.36. March 3. General Assembly. New York. http://unstats.un.org/unsd/dnss/ gp/FP-New-E.pdf.

[5] United Nations Statistics Division, UNSD (2015). United Nations Fundamental Principles of Official Statistics - Implementation Guidelines, New York. http://unstats.un.org/unsd/ dnss/gp/impguide.aspx. 